\title{
AN EXPLORATORY FACTOR ANALYSIS OF THAINESS EXPERIENCE-CENTRIC SERVICE CONSTRUCTION FOR BOUTIQUE HOTEL GUESTS
}

\author{
Thanasit SUKSUTDHI* \\ National Institute of Development Administration (NIDA), Graduate School of Tourism Management, Thailand, e-mail: thanasit.suk@ stu.nida.ac.th \\ Watsida BOONYANMETHAPORN \\ National Institute of Development Administration (NIDA), Graduate School of Tourism Management, Thailand, e-mail: worarak.suc@ nida.ac.th
}

\begin{abstract}
Citation: Suksutdhi, T., \& Boonyanmethaporn, W. (2022). AN EXPLORATORY FACTOR ANALYSIS OF THAINESS EXPERIENCE-CENTRIC SERVICE CONSTRUCTION FOR BOUTIQUE HOTEL GUESTS. GeoJournal of Tourism and Geosites, 40(1), 96-103. https:// doi.org/10.30892/gtg.40111-807
\end{abstract}

\begin{abstract}
The COVID-19 outbreak has inevitably impacted the global hotel industry, which will result in a shift from traditional services to personalized and specialized services to reduce the confrontation. This study was to examine the characteristics of Thainess experience-centric service (TECS), based on the perspective of boutique hotel guests during the COVID-19 pandemic, to develop and test scales for measuring TECS, a new component of boutique hotel services in Thailand. The quantitative method was administered. Multi-stage sampling was approached, and questionnaires were used to collect data from 112 self-identified boutique hotel guests via an online survey by Google form to examine the TECS attributes. Exploratory Factor Analysis (EFA) was used to refine the final instrument. The development process results in a reliable and valid TECS feature scale under the perspective of boutique hotel guests. It consists of 28 measurement scales that combine the services of a Thainess experience service, Thai atmosphere value, and Thai hospitality. To investigate attributes of Thainess experience-centric service (TECS) referring to the perspectives of boutique hotel guests to develop and test a scale for measuring the TECS, a new component of boutique hotel services. The quantitative approach was employed by using exploratory factor analysis (EFA). A study of 112 self-identified boutique hotel guests with a multi-stage sampling approach via an online survey by Google form during the COVID-19 pandemic. The TECS attributes under the perspectives of boutique hotel guests consisting of a 28 -item measurement scale incorporating Thainess experience service, Thainess atmosphere value, and Thai hospitality. Boutique hotel guests also demonstrated their preferences towards hotel services as well as the basic demographic profiles and characteristics, which are useful for implementing hotel strategy enhancing guests' satisfaction and exceed their expectations prior to the COVID-19 pandemic. The authors would recommend applying the TECS to refocus its practices to creates the guest experience in the hotel business. This research contributes towards value creation by using the strategy of cultural value in creating high-quality standards and it can create a positive experience and guest's satisfaction. Hence, the cultural value of each society can be considered for creating the guest experience.
\end{abstract}

Key words: thainess, experience-centric service, Boutique Hotel, Hotel Guests, COVID-19 pandemic

$* \quad * \quad * \quad * \quad * \quad *$

\section{INTRODUCTION}

Tourism Authority of Thailand (TAT) has used the concept of "Thainess" as a marketing tool to promote tourism and has created the Thainess experience since 2015. A campaign has been defined to attract tourists to experience Thai nature, learn the essence of Thai roots through various campaigns such as Discover Thainess or Amazing Thai Tay (Amazing Thai chic). To create value-added, it has used the strategy of Thainess's perceived value instead of selling goods and services from the previous practice, as well as to emphasize positive communication, high quality, and standards of products and services. In addition, the extension of values awareness, awakening, and encouraging the pride of Thainess among Thai people while the Thai way of life of the country is maintained (Nirattrakul, 2015). The Thai represents the service-minded character that has been unparalleled in the world. It is existing in the Thai people since they were born, which foreigners have perceived under the name of Thailand, "Land of Smile" (TAT, 2015). It has described as a world-class and personalized service, consequently, resulting in positive experience and satisfaction (Kasivivat, 2018). In addition, Thai considers as a non-touch society that begins with a Wai; the folding of both hands together with the head bowing and no handshake, which has become old-fashioned during the COVID-19 pandemic and helps to reduce service encounters with many employees and confrontations with other guests to prevent the disease epidemic (Kongpolphrom, 2018).

The COVID-19 pandemic has severely hurt the hotel industry, however there is hope the pandemic will end soon following mass vaccination programs. Hence, the hotel industry will more greatly reset with declining traditional ways of service systems (Toubes et al., 2021). A slow-growth recovery after the COVID-19 pandemic can help hotel businesses survive which is looking to continue its boom with caused intense competition after the pandemic (Sassen and Kourtit, 2021). The use of different strengths as a strategy to create guest's experience, value-added, and having higher standards for hotel products and services will be considered the business opportunity (Chan et al., 2021).

\footnotetext{
* Corresponding author
} 
Thainess service allows guests to have a good attitude, perceived the true meaning, and creating a better balance between interpretations and imagination (Kasivivat, 2018). However, using the strengths and values of Thainess service as a tool to create experiences requires a holistic approach (Brozović et al., 2020). Hence, effective management of Thainess service can be an important tool in the competitiveness of the global hospitality industry (Fakfare et al., 2019; Sucher et al., 2013). Thainess can be created a different guest experience that has a positive effect on mental and emotional values (Nirattrakul, 2015). Especially boutique hotel that has a unique story of its own, the brand's concept, the history of the place, or the owner's passion for something through the architecture and interior, the property, and the service model which attracts guests with its own unique selling point and services (Day, 2013).

Thus, the implementation of the uniqueness of Thainess to the boutique hotel's service can be considered as an interesting strategy post-COVID-19 pandemic. In addition, guest behavior will be changed significantly. The pressure of the pandemic will have infiltrated every aspect of the guest experience. For instance, expert guests will have a different relationship with where they spend a week and the way to choose to relieve stress, the family guest will have new priorities, and the individual guest will have altered relationships with the luxury. This will be making short-term expectations and changes in travel behavior, practices, and priorities permanently altered over the long term as well as health and safety are a public and personal responsibility concerned. Hence, boutique hotel organizational practices will also have to be changed, the guests engage in a completely different conversation, and it is imperative that hotel management learn to deepen their understanding of the ever-challenging situation (Chan et al., 2021; Sassen and Kourtit, 2021). The experience-centric service concept focuses on the customers' experience and value creation. The experience will be designed directly in a believable way following the organization's desire to deliver a specific customer experience. It should be able to reach the customer's feelings and thoughts deeper and create a memorable and impressive experience in various forms (Lemon and Verhoef, 2016). Furthermore, encourage customers to interact, participate, and being a part of activities or services (Clark and Myers, 2018). Thainess experience-centric service has used the distinction and cultural differences as variables in determining guest journey and service touchpoints. To encourage the guest to interact and feel engaged with the Thainess service context, able to access the emotional, physical, mental, feelings, and memory of the guests deeply (Khan et al., 2015). As a result, it creates the guests' distinct experience, satisfaction, and revisiting (Fakfare et al., 2019; Sucher et al., 2013).

There are studies (e.g.: Gołąb-Andrzejak and Gębarowski, 2018; Kozak and Acar, 2015; Zhong et al., 2017) in various dimensions to create impressive experiences in the hotel business which can be grouped as 1) the designing experience research in various issues, mostly focused on policy, process, and innovation experience that hotel services consist of many touchpoints, where experiences should be examined, and each of moments of contact with the brand should be incorporated into an integrated process of hotel guest experience management (Gołąb-Andrzejak and Gębarowski, 2018); 2) the service experience research related to Thai culture mostly focused on the results, processes, methods, and effects of guests' behavior which the hotel had implemented Thai culture in the service areas and was able to deliver guest satisfaction (Sukkha and Peinroj, 2015); and 3) the service design elements research mostly related to staff participation, the management of guests, and the close engagement of back of house employees and front of house activities which represented promising new frontiers in experience design (Beltagui and Candi, 2017), the hotel should focus on the whole service experience through the created value (Kozak and Acar, 2015). However, guest experience research related to the hotel business has been explored (Sukkha and Peinroj, 2015); yet its lack of Thainess experience-centric service study which unclear and limited forms in guest's experience, especially in the boutique hotel business in Thailand.

Thus, this study was aimed to investigate the attributes of Thainess experience-centric service referring to the perspectives of boutique hotel guests during the COVID-19 pandemic. Given the scarcity of research on experiencecentric service in Thai boutique hotels based on Thainess, filling significant research gaps to measure services that emphasize the Thai experience with an in-depth understanding of boutique hotel guest perceptions. It provides a tool to identify the guest's preference in the experience-centric services and to evaluate the boutique hotels' performance in providing the Thainess service provision. In addition, the measurement scale developed in this study serves as the foundation for future research, which may help to stimulate further empirical research on the relationship analysis of Thainess experience-centric service and hotel guests' experience towards their satisfaction. It also gives boutique hotel practitioners information about the profiles, characteristics, and preferences of the substantial number of guests who would consider staying in Thai boutique hotels providing Thainess services. Moreover, boutique hotel management has a new tool to use in assessing the experience-centric service of the hotel with more insights into what aspects of the hotel they should focus on to influence guest satisfaction and behavioral intention.

\section{LITERATURE REVIEW}

Thainess is a Thai culture that can be seen everywhere in Thailand (TAT, 2015). It is a symbol of Thai identity in relating to the culture of the country that can recognize immediately and has a positive effect on mental values and feelings (Kasivivat, 2018). It is complex, multi-dimensional, moving, and always changing in both traditional and contemporary styles. Thainess has been also interpreted and given various meanings in different contexts, including a way of life, beliefs, and relationships, both directly and indirectly, and has been modifying to the current living (Nirattrakul, 2015). There should be able to convey to understand the meaning of Thainess of Thailand which results in a worthwhile and impressive experience (Department of Cultural Promotion, Ministry of Culture, 2016). In addition, it is a predictor of a warmth memorable experience to meet the guests' needs, expectations, and make guests' satisfaction which can be considered as a measure of service success (Khadka and Maharjan, 2017). Many scholars (e.g.: Kasivivat, 2018; Sukkha and Peinroj, 2015; 
Supploy, 2018) have defined Thainess in many aspects which may be difficult to understand and has unclear meanings. However, Thainess in the hospitality perspective in Thailand, most of which are explained in cultural dimensions, uniqueness, and identity of the Thai national (Fakfare et al., 2019; Nirattrakul, 2015). Thainess has also been perceived as a Thai cultural value, which is a utility derived from the exchange in the form of acquisition value and transaction value towards the elements and quality of Thainess service. It is caused by analytical thinking from concepts, beliefs, periods of time, effort, price, and quality of Thainess products and services with the involvement of emotion, society, and cultural factors. As a result, contributing guest's satisfaction and revisit in which guests will assess to various factors from the products and services components based on the Thainess experience service (Khadka and Maharjan, 2017).

Thainess provides a positive experience of the service quality, and affects guest's satisfaction, and revisit intention directly. It has been explained in the hotel context through the physical characteristics and the atmosphere presented by the traditional and contemporary Thai art and architecture, the characteristics of the Thai service that uses personnel is welcoming and serving with Thai etiquette, and methods of producing Thai food using values some Thai wisdom and Thai way of life have been chosen to present the science of Thai cooking based on the type and nature of the place (Fakfare et al., 2019; Nirattrakul, 2015). Moreover, Thainess service in the hotel has also been mentioned include Wai, smile, sincerity, forgiveness, softness, warmth, empathy, humility, morality, courtesy, helpfulness, modesty, respectfulness, kindness, loyalty, friendship, and service-minded attitude (Sucher et al., 2013).

Thainess has been adopted in the hotel operations both tangible and intangible services. Many hotels have applied Thainess to the elements and the uniqueness of their service (Beltagui and Candi, 2017; Supploy, 2018). The Dusit Thani hotel has created a hotel vision based on a uniqueness of Thai culture and traditions to provides outstanding hospitality and meet the guest's needs (Kalanon, 2012). As a result, it has been perceiving as world-renowned today in Thainess service quality. In addition, many international hotel chains in Thailand have used the Thainess decoration concept as a selling point, for instance, the Bangkok Marriott Hotel the Surawongse has adopted contemporary Thai arts and Chang Sip Mu art (Ten Crafts) to decorate the hotel both in the public areas and in the guest rooms, which are able to impress the guest and able to create the Thainess atmosphere reasonably (Supploy, 2018).

The experience economy concept illustrates that presenting the previous concepts of products and services might be inadequate for the current competition, whereas creating an experience for customers from using products and services in various forms will have the most influence (Pine and Gilmore, 1998). The customer experience concept is focusing on providing customers a memorable experience and being able to relive past experiences with the organization. It is emphasizing the results of thoughts, emotions, feelings, and memory to create psychological value that customers can recognize by their own analysis (Kandampully et al., 2018). Furthermore, the customer experience is able to create independently, which occurs both direct and indirect and at different times, planned and unplanned, and able to occur before, during, and after using the service (Gołąb-Andrzejak and Gebarowski, 2018).

Hence, the customer experience begins when customers decide to use the service or communicate with service providers (Lemon and Verhoef, 2016) and can occur anywhere along the service route of the customer journey (Seligman, 2018). Customer experience value arises from the interaction between customers and the organization in every dimension and every moment. It has been created from seeing, hearing, observing, participating, the influence of surrounding service context, and previous experience that creates the customer's memory and emotions (Zhong et al., 2017). However, the customer experience is based on individual interpretation, and the different times and locations. Therefore, there is a limitation of the service providers to consider designing the customer experience carefully and clearly (Seligman, 2018). Many scholars have explained the corresponding customer experience values that resulting from knowledge, derived from the observation, encountering, performing, and brought to the memory which is diverse and different in the natural and social sciences. It is self-learning that has a unique meaning and is related to the senses, feel, think, act, and relation (Lemon and Verhoef, 2016). Customer experience in the hotel context is relevant to thinking, formulating, planning, and developing a unique guest experience model. It affects the idea and creates innovation in value of product and service and encourage guests to understand the purpose of the service provider (Beltagui and Candi, 2017). The hotel guest experience focuses on experience creation that follows the hotel's intention (Zhong et al., 2017). However, creating a guest experience should have an effective management plan, having thorough research carefully, and changing until the experience creation is appropriate. In addition, it requires an understanding of the needs, motivation, and expectations of the guests deeply (Lemon and Verhoef, 2016).

The experience-centric service is an experiential marketing approach developed from the concept of customer experience and customer-centric service. It focuses on the customer's experience and defines as a specific experience that the organization intend to provide for the customer which believes that it will be able to reach the customer feelings and thoughts deeply (Lemon and Verhoef, 2016). The experience-centric service is used to design an impressive experience. It focuses on the intended experience offering to the customers and able to encourage customers to interact, participate, and being a part of the activities or service elements to create an experience in various forms (Beltagui and Candi, 2017). Furthermore, there should be able to communicate and access guests' emotions in all aspects, including physical, emotional, mental, feeling, and memory. Hence, the design of guest's experience-centric service requires a process of assessing and reviewing, which should be able to amend according to the context, situation, and guests' behavior. It is enabling the hotel to design an experience that appropriates the guests' behavior (Clark and Myers, 2018).

Thainess experience-centric service (TECS) is the integration of the experience-centric service and Thainess concept (Beltagui and Candi, 2017; Tourism Authority of Thailand, 2015). TECS focuses on creating cultural value from the Thainess service experience, using the cultural distinction of Thainess as variables in determining guests' journey and 
service touchpoints (Beltagui and Candi, 2017). To encourage the guests to interact and feel engaged with Thainess service activities. To access the emotional, physical, mental, feelings, and memory of the guests deeply (Lemon and Verhoef, 2016). As a result, creating the guest's positive experience, satisfaction, and impressions of the service (Fakfare et al., 2019). Thainess experience-centric service needs a holistic approach to work integration and clear policy (Brozović et al., 2020). Guests' journeys and service touchpoints need to be determined and work collaboration from various parts; front and back staff, executive management team, and hotel service activities that contribute to the memorable experience. Furthermore, the guest experience value measurement needs to be based on guest satisfaction which results from the positive experience that occurs while guests using the service (Zhong et al., 2017).

The guest's satisfaction is the single factor that comes from products and services evaluation and previous experience which is caused by guest expectations and service quality (Khadka and Maharjan, 2017). The elements of the guest's satisfaction evaluation are consisting of environmental setting, service employees, service delivery process, fellow customers, and back-office support employees. However, creating guest satisfaction through experience-centric service is a creation of a positive feeling, satisfaction, and emotional engagement for the guests (Gołąb-Andrzejak and Gębarowski, 2018; Zhong et al., 2017). Especially Thainess, which gives profound meaning and value, differences and are accepted around the world, able to create the Thainess service experience value and causing the positive guests' memory and guest satisfaction respectively (Fakfare et al., 2019; Sukkha and Peinroj, 2015). In this study, an extensive literature review has been conducted to identify relevant TECS attributes through systematic literature analysis.

The scale of TECS development was finally determined as the literature references from previous studies which based on 1) Thai food (Kalanon, 2012), 2) Thai arts (Supploy, 2018), 3) The Thai way of life (Nirattrakul, 2015), 4) Thai wellness (Sukkha and Peinroj, 2015), 5) Thai festivals (TAT, 2015), 6) Thai wisdom (Department of Cultural Promotion, Ministry of Culture; 2016), 7) Thai's fun (Kasivivat, 2018), and 8) Thai hospitality (Fakfare et al., 2019). Hence, the final determination of TECS attributes from a literature review can be summarized into 5 components as follow 1) Thai hospitality (Fakfare et al., 2019), 2) Thai arts, the physical setting (Supploy, 2018), 3) Thai way of life (Nirattrakul, 2015), 4) Thai food service (Kalanon, 2012), and 5) Thai wellness service (Sukkha and Peinroj, 2015). From those TECS attributes, it has been developed to be the questionnaire for this study which has 31 question items. The questionnaire was asking covering all 5 components according to the literature review, which includes Thai hospitality 15 question items, Thai arts, the physical 5 question items, Thai way of life 4 question items, Thai food service 4 question items, while Thai wellness service consists of 3 question items.

\section{MATERIALS AND METHODS}

A pure quantitative research method was conducted with the study of 112 self-identified both Thai and international boutique hotel guests in Bangkok during the COVID-19 pandemic. Based on the scale development procedure (Churchill, 1979), various reliability and validity tests have been carried out to confirm the scale structure, include four steps as follow,

1) initial items development derived from the literature review includes 31 variables that are extracted from both tangible and intangible components. The tangible components consist of Thai hospitality (Fakfare et al., 2019), Thai arts, the physical setting (Supploy, 2018), Thai way of life (Nirattrakul, 2015), Thai food service (Kalanon, 2012), and Thai wellness service (Sukkha and Peinroj, 2015). Likewise, intangible components include Wai, smile, sincerity, forgiveness, softness, warmth, empathy, humility, morality, courtesy, helpfulness, modesty, respectfulness, kindness, loyalty, friendship, and service-minded attitude (Sucher et al., 2013).

2) purifying measure implementation; the developed questionnaires were sent to three experts for content validity checking and the language used to cover and match the specified definition. The questionnaires have been amended according to expert suggestions by evaluating the content validity of each test, using the IOC formula to find the average of the consistency index of all experts. After the evaluation by the experts from the hotel business and academic, the number of measurement items has reduced to 28 , with the IOC consistency index was between 0.5-0.7, and the 3 rejected items where index was 0.3 includes assistance from staff, Thai language, and staff interaction.

3) data collection has taken online due to the given COVID-19 pandemic situation, it is imperative to prevent the spread of the disease, therefore, online data collection methods by Google form have been applied. This research has used a multi-stage sampling method of 112 samples; the first step, Bangkok was selected as the data collection area, and the second step was to select boutique hotels in Bangkok by allowing guests to answer online surveys. It is an estimation scale questionnaire with criteria for determining the weight of the assessment into 5 levels according to Likert's scale method. The self-administered questionnaire covers the content and objectives of the study by selecting questions with the objectives of the content from level 0.5 and above only (Cronbach, 1970).

4) exploratory factor analysis has been used to purify and reliability measurement after collecting the data. It has been applied to identify groups of variables and to reduce a data set to a more manageable size. Since the items used in this study were derived from previous literature that has been conducted in Thai hotels. However, exploratory factor analysis was used in this study to purify and reliability in the contexts of Thai boutique hotels and during the COVID-19 pandemic situation (Kongpolphrom, 2018; Day, 2013). After exploratory factor analysis, there were none of the items deleted. Kaiser-Meyer-Olkin showed the Thainess experience-centric service factor was at 0.944 which indicated the measurement items developed were reliable and valid. Bartlett's Test of Sphericity estimated by using the chi-square distribution was at 3773.997 , the significant value was equal to 0.000 , and the Cronbach's alpha of the total scale was 0.982. And then, analysing the confidence to get Cronbach's alpha coefficient of 0.70 (Nunnally, 1978). 
The data was analyzed by employing descriptive statistics to describe personal profile of the respondents include gender, age, nationality, level of education, occupation, marital status, and average monthly income. Behavior of hotel guest include objective for traveling, number of nights stay at the hotel, average expenses per stay, number of stays at the hotel within a year, who are you traveling with, the reason for choosing to stay at the hotel with Thainess service, source of information about the hotel? the area you choose to stay, modes of transport to hotel, and period of stay at the hotel. Exploratory factor analysis was performed to refine the final instrument and is used to group the variables that are related to the same group. The components were extracted by analyzing the main components and rotate the axis in an orthogonal way by using Varimax with the Kaiser Normalization method. The appropriate factor loading is up from 0.5 . Figure 1 below shows the process of research methodology.

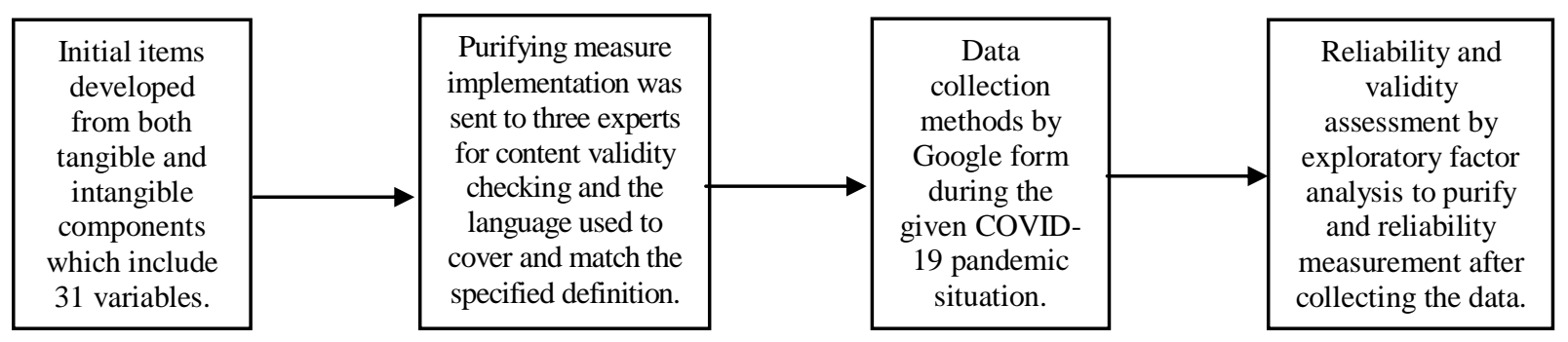

Figure 1. Flow Chart of Research Methodology

\section{RESULTS AND DISCUSSION}

The demographic profiles of all 112 respondents revealed that most of them were 67 males accounted for $59.80 \%$ and 45 females accounted for 40.20\%. A great number of the sample were Generation Y (21 - 38 years old) amount of 62 people accounted for $55.40 \%$. Mostly were Thai nationals' amount of 39 people accounted for $34.80 \%$, 56 people who graduated with a bachelor's degree accounted for $50.00 \%$, and they were the private company employees amount of 41 people accounted for $36.60 \%$. A large group of respondents were the single status amount of 87 people accounted for $77.70 \%$, and the monthly income level was more than 1407 USD amount of 58 people accounted for $51.80 \%$. The behavior of hotel guests illustrated leisure/traveling purpose amount of 88 people (78.60\%).

The number of nights stay at the hotel was around 2-4 nights amount of 80 people (71.40\%). About 29 people had expenses per stay that were more than 167 USD (25.90\%). The number of stays at the hotel within a year was 1 - 2 times, amount of 54 people (48.20\%). And about 49 people travelled with friends $(43.80 \%)$. In addition, they chose to stay at the hotel with the Thainess location and locality reason amount of 47 people accounted for $42.00 \%$. They searched the hotel information from the hotel booking application amount of 32 people (28.50\%). Phuket province was famous area amount of 33 people (29.50\%) and 44 people used private cars for traveling (39.30\%). Lastly, the sample group mostly stayed at the hotel during vacation, amount of 34 people accounted for $30.4 \%$.

After determining the content of 31 Thainess experience-centric service question items. The number of measurement items has reduced to 28 , with the IOC consistency index was between $0.5-0.7$, the 3 rejected items where index was 0.3 includes assistance from staff, Thai language, and staff interaction. The analysis results of reliability and validity of the questionnaire of Thainess experience-centric service from a sample of boutique hotel guests revealed that Cronbach's alpha analysis results of all items were greater than 0.70, which were Thai hospitality was between 0.980-0.982, Thai Arts, the physical setting was between 0.980-0.981, and the Thai way of life, Thai food service, and Thai wellness service were equally to 0.981 . Thus, the questionnaire was considered reliable and could be used to analyze the data. Kaiser-MeyerOlkin and Bartlett's Test of Sphericity is two statistical calculations test. The research results obtained a Kaiser-MeyerOlkin of 0.944 , which is greater than 0.5 and close to 1 , indicating that all data and variables were highly correlated and could be used for factor analysis of the research objectives. Likewise, the Bartlett's test should be statistically significant (Sig. $<0.05$ ) and the Sig. value of 0.000 , which is less than 0.05 indicates that the correlation matrix is not an identity matrix (Vanichbuncha, 2019). Hence, all 28 variables are related enough for factor analysis as shown in Table 1 below.

Table 1. Kaiser-Meyer-Olkin and Bartlett's Test

\begin{tabular}{|c|c|c|}
\hline \multicolumn{2}{|c|}{$\begin{array}{c}\text { Kaiser-Meyer-Olkin } \\
\text { Measure of Sampling } \\
\text { Adequacy }\end{array}$} & 0.944 \\
\hline \multirow{2}{*}{$\begin{array}{c}\text { Bartlett's } \\
\text { Test of } \\
\text { Sphericity }\end{array}$} & $\begin{array}{c}\text { Approx. } \\
\text { Chi-Square }\end{array}$ & 3773.997 \\
\cline { 2 - 3 } & df & 378 \\
\hline
\end{tabular}

Table 2. Kaiser-Meyer-Olkin and Bartlett's Test

\begin{tabular}{|c|c|c|c|c|c|c|c|c|c|}
\hline \multicolumn{10}{|c|}{ Total Variance Explained } \\
\hline \multirow{2}{*}{$\begin{array}{c}\text { Com- } \\
\text { ponent }\end{array}$} & \multicolumn{2}{|c|}{ Initial Eigen Values } & \multicolumn{3}{|c|}{$\begin{array}{c}\text { Extraction Sums } \\
\text { of Squared Loadings }\end{array}$} & \multicolumn{3}{|c|}{$\begin{array}{c}\text { Rotation Sums } \\
\text { of Squared Loadings }\end{array}$} \\
\cline { 2 - 10 } & Total & $\begin{array}{c}\text { \% of } \\
\text { Variance }\end{array}$ & $\begin{array}{c}\text { Cumula- } \\
\text { tive \% }\end{array}$ & Total & $\begin{array}{c}\% \text { of } \\
\text { Variance }\end{array}$ & $\begin{array}{c}\text { Cumula- } \\
\text { tive \% }\end{array}$ & Total & $\begin{array}{c}\% \text { of } \\
\text { Variance }\end{array}$ & $\begin{array}{c}\text { Cumula- } \\
\text { tive \% }\end{array}$ \\
\hline 1 & 18.829 & 67.246 & 67.246 & 18.829 & 67.246 & 67.246 & 8.097 & 28.919 & 28.919 \\
\hline 2 & 1.455 & 5.197 & 72.443 & 1.455 & 5.197 & 72.443 & 7.763 & 27.725 & 56.644 \\
\hline 3 & 1.145 & 4.089 & 76.532 & 1.145 & 4.089 & 76.532 & 5.569 & 19.888 & 76.532 \\
\hline
\end{tabular}

Table 2 below shows the determination of initial communality from the Maximum Likelihood method assumes that initial is a value that indicates whether a variable is good to compare to other variables. Extraction communality of a variable after extraction of the factors found that the value extraction communality of the TECS1 variable was the lowest $=0.597$, but it was still not very low and could be clearly classified as one of the components. To find the 
variance (Total Variance Explained) from the analysis, three components can be identified with the eigenvalue range of 1.145-18.829 and the cumulative variance of 76.532 percent. Component 1 describes the total variation $67.246 \%$, Component 2 describes the total variation 5.197\%, and Component 3 describes the total variation $4.089 \%$.

From Table 3, the researcher chose the maximum likelihood axis rotation method using the varimax method. It found that the factor loading value changed compared to the factor loading value before the rotation of the axis. From the varimax axis rotation equal to the correlation coefficient between the variable and the rotating component, it found that the variables with a large factor loading of each component as follows, component 1 consists of 12 variables: Thai aroma, Thai herbs personal care, Thai herbs products, Thai food knowledge, Thai food identity, taste of Thai food, Thai food decoration, Thai style uniform, eye contact, smile, greet with Wai, and gentle service. All 12 variables have an eigenvalue of 18.829 and a component weight between $0.489-0.803$. It has an explanatory variance of 67.246 percent, named "Thainess Experience Service". Component 2 consists of 12 variables: warm service, attentiveness, respectfulness, thanks, politeness, Thainess facilities, Thai art, Thai identity decoration, the charm of Thai style atmosphere, invitation to return to the service, local products and services providing, and Thainess decoration in the guest room. All 12 variables have an eigenvalue of 1.455 and component weights between $0.577-0.793$. It has an explanatory variance of 5.197\% named "Thainess Atmosphere Value". And component 3 consists of 4 variables: sincere service, enthusiasm of the service, friendliness, and humble service. All 4 variables have an eigenvalue of 1.145, with a component weight ranging from $0.714-0.851$, with an explanatory variance of 4.089 percent, named "Thai Hospitality".

Table 3. Rotated Factor Matrix Value

\begin{tabular}{|l|c|c|c|}
\hline \multicolumn{1}{|c|}{ Variables } & \multicolumn{3}{|c|}{ Factor } \\
\hline & $\mathbf{1}$ & $\mathbf{2}$ & $\mathbf{3}$ \\
\hline 26. The hotel area has the scent of Thai aroma. & 0.803 & & \\
\hline 27. The hotel offers personal care products made from Thai herbs. & 0.797 & & \\
\hline 28. You have used personal products made from Thai herbs in hotel. & 0.766 & & \\
\hline 25. You have gained knowledge of Thai food. & 0.760 & & \\
\hline 22. Thai food service clearly indicates Thai identity. & 0.744 & & \\
\hline 24. Thai food in the hotel tastes delicious to your palate. & 0.723 & & \\
\hline 23. Thai food decoration reflects Thai identity. & 0.644 & & \\
\hline 21. Staff uniform represents Thai style. & 0.642 & & \\
\hline 3. Staff always make eye contact during the service. & 0.659 & & \\
\hline 2. You always received service with a smile. & 0.540 & & \\
\hline 1. Staff greeted you with Wai. & 0.498 & & \\
\hline 4. You feel a gentle service. & 0.489 & & \\
\hline 12. You always feel warm when you use the hotel service. & & 0.793 & \\
\hline 10. You received the service attentiveness. & & 0.774 & \\
\hline 11. You perceived respect in service. & & 0.767 & \\
\hline 13. You always received thanks after using the service. & & 0.725 & \\
\hline 9. Staff service you politely. & & 0.695 & \\
\hline 15. The hotel facilities are built on the concept of Thainess. & & 0.694 & \\
\hline 19. You can experience various forms of Thai art in hotel. & & 0.656 & \\
\hline 18. The hotel's restaurant decoration reflects Thai identity. & & 0.653 & \\
\hline 16. You can feel the charm of Thai style from surrounding area. & & 0.648 & \\
\hline 14. You are invited to use the service again. & & 0.602 & \\
\hline 20. The hotel uses local products for service purposes. & & 0.587 & \\
\hline 17. The guest rooms are decorated with Thai uniqueness. & & 0.577 & \\
\hline 5. You perceive the sincere service. & & & 0.851 \\
\hline 8. You see the enthusiasm of the service. & & & 0.795 \\
\hline 6. Staff provide you a friendly service. & & & 0.746 \\
\hline 7. You feel the humble service. & & & 0.714 \\
\hline
\end{tabular}

Table 4. Components Group Assignment

\begin{tabular}{|l|c|}
\hline \multicolumn{1}{|c|}{ Component's name } & $\begin{array}{l}\text { Number of } \\
\text { Variables }\end{array}$ \\
\hline $\begin{array}{l}\text { Component 1 Thainess } \\
\text { Experience Service }\end{array}$ & 12 \\
\hline $\begin{array}{l}\text { Component 2 Thainess } \\
\text { Atmosphere Value }\end{array}$ & 12 \\
\hline Component 3 Thai Hospitality & 4 \\
\hline \multicolumn{1}{|c|}{ Total } & 28 \\
\hline
\end{tabular}

The author obtained the results of arranging variables into components and naming elements which can be organized into 3 components and divided variables as shown in Table 4. The varimax axis rotation found 3 components which has an eigenvalue between $1.145-18.829$ and has an explanatory variance of $76.532 \%$.

It means the components found can account for $76.532 \%$. This may be because the author has reviewed the literature of the Thainess experiencecentric service clearly which consists of (1) Thainess experience service (TES) consists of 12 variables; Thai aroma, Thai herbs personal care, Thai herbs products, Thai food knowledge, Thai food identity, taste of Thai food, Thai food decoration, Thai style uniform, eye contact, smile, greet with Wai, and gentle service.

It can be used as variables to determine the guests' journey and service touchpoints and can encourage guests to interact and feel engaged with service activities and the surrounding. It can access the emotional, physical, mental, feelings, and memory of the guests deeply (GołąbAndrzejak and Gebarowski, 2018; Kandampully et al., 2018). As a result, creating the guests' positive experience, satisfaction, and impressions. Thus, TES can be used as a service concept for the hotels to encourage guests to participate in the hotel services and facilities. Moreover, considering the guest journey and service touchpoints by using TES is creating their memorable experience and resulting in the returning for service; (2) Thainess atmosphere value (TAV) consists of 12 variables; warm service, attentiveness, respectfulness, thanks, politeness, Thainess facilities, Thai art, Thai identity decoration, Thai atmosphere, invitation to return to the service, local products, and services, and Thainess decoration in the guest room. It can create value, satisfaction, and emotional engagement. Especially, Thainess gives profound meaning, positive experience, value, differences and are accepted around the world (Fakfare et al., 2019; Supploy, 2018). Hence, TAV can be determined as the service guideline to create the value of Thainess and causing positive experience and customer satisfaction respectively. However, to create value perception and their impressive service experience among guests all variables are important to consider. 
The Thai boutique hotel is necessary to adapt to the service standard and hotel facilities; (3) Thai Hospitality (TH) consists of 4 variables: sincere service, enthusiasm of the service, friendliness, and humble service. It can create warmth and guests' satisfaction, meet the guests' needs and a memorable experience, as well as providing services that exceed their expectations can be considered as a measure of service success (Fakfare et al., 2019; Sucher et al., 2013). Thus, TH is considered important for providing services in Thai hotels, which are considered valuable cultural heritage resources without having to pay for purchases and are still inherent in Thai employees since were born with none to imitate. Most importantly, TH can also cause a feeling of warmth and comfort to the guests.

\section{CONCLUSION}

The development process results in a reliable and valid scale of Thainess Experience-centric service attributes under the perspectives of boutique hotel guests consisting of a 28-item measurement scales incorporating three dimensions: Thainess Experience Service, Thainess Atmosphere Value, and Thai Hospitality. Boutique hotel guests also demonstrated a preference towards hotel services as well as the basic demographic profiles and characteristics, which are useful for implementing hotel strategy enhancing guests' satisfaction and exceed their expectation prior to COVID-19 pandemic. Especially, the Thai single young male (Generation Y), who graduated with a bachelor's degree, and as a private company employee with a monthly income of more than 1407 USD. The purpose for travelling was leisure and stayed at the hotel for around 2-4 nights at the expense of more than 167 USD. Within a year, they came back to the hotel 1 - 2 times with friends and preferred the hotel location in the Thainess local area. In addition, they used the hotel booking application and like to go to Phuket with private car during their vacation. Hence, this group of guests who preferred to experience Thainess service and perceived Thainess value is considered as an interesting target group for Thai boutique hotels.

The originality of this research is highlighted in several points. The concept of Thainess as a marketing tool is used to create Thainess experience; it is considered as a personalized service that reflects the prevention of the disease epidemic with confrontation avoidance effectively (Kongpolphrom, 2018). Thainess as non-touch society variable in determining hotel guests' journey and service touchpoints in the hotel to encourage guests to interact and engaging with Thainess service activities surrounding, as a result, it can create a positive experience and guest's satisfaction (Fakfare et al., 2019; Kasivivat, 2018; Sucher et al., 2013). To create the Thainess experience service (TES) and encourage guests to interact and feel engaged with service activities. The hotel should initially identify the guests' journey and service touchpoints clearly. The component of service variables of TES and the application properly should be considered. For instance, all staff should wear Thai style uniform weather style or fabric, greet the guest with Wai, make eye contact, smile, and provide gentle service. Thai ascent aroma, Thai-style decoration, and offer personal care products made from Thai herbs in public areas and guest room should be provided. Staff should offer a tale of Thai food while serving, Thai food presentation and taste should represent the Thai identity explicitly. These can help to access the emotional, physical, mental, feelings, and memory of the guests while using the service deeply. In addition, the hotel should apply the TES to be the service model, this is able to enhance the guest satisfaction and their memorable experience.

To create the Thainess atmosphere value (TAV) and increase high-quality values and standard of hotel products and services. The hotel should focus on TAV variables as the service guideline. For instance, staff should provide warm service, politeness, attentiveness, respect for all guests without discrimination, and provide thanks after the guest has completed the service. Hotel facilities should be decorated in the form of Thai arts and represent Thai identity clearly. Invitation to return to the service should be always offered. In addition, local products and services should be decorated in the guest room. These are causing positive guest memory and satisfaction. However, the hotel is necessary to train TAV for the hotel service standard. This is to remind staff giving importance to the Thainess service value. Moreover, the hotel will be having an efficient service tool to create Thainess atmosphere value.

Finally, to create warmth and satisfaction, meet the guests' needs, and create a memorable experience. The hotel should encourage Thai hospitality $(\mathrm{TH})$ to be the service standard. For instance, encourage staff to provide service sincerity, enthusiasm of service, friendliness, and humble service. TH should be always evaluated; however, the hotel may need to plan for selecting the potential staff with the Thainess service-minded and positive attitude.

In summary, Thainess experience-centric service (TECS) is considered one different strategy model for creating an impressive and memorable service experience. It can access the emotional, physical, mental, feelings, and memory of the guests deeply, especially for boutique hotels that need to create their own identity. TECS is also considered a personalized service which is important during the COVID-19 pandemic that can help to reduce the service encounter and the guest's confrontation while using the service. In addition, increasing the value perception and gives importance to individual guests. Moreover, this research contributes towards value creation by using the strategy of cultural value. Hence, the cultural value of each society can be considered for creating the guest experience and high-quality standards, and it can create a positive experience and guest satisfaction.

\section{REFERENCES}

Beltagui, A., \& Candi, M. (2017). Revisiting service quality through the lens of experience-centric services. International Journal of Operations \& Production Management, 38(3), 915-932. https://doi.org/10.1108/IJOPM-06-2015-0339

Brozović, D., D’Auria, A., \& Tregua, M. (2020). Value Creation and Sustainability: Lessons from Leading Sustainability Firms. Sustainability, 12(11), 4450. https://doi:10.3390/su12114450

Chan, I.C.C., Ma, J., Ye, H., \& Law, R. (2021). A Comparison of Hotel Guest Experience Before and During Pandemic: Evidence from Online Reviews. Information and Communication Technologies in Tourism, 549-556. https://doi.org/10.1007/978-3-030-65785-7_52 
Churchill, G.A. (1979). A Paradigm for Developing Better Measures of Marketing Constructs. Journal of Marketing Research, 16(1), 64-73. https://doi.org/10.2307/3150876

Clark, M., \& Myers, A. (2018). How customer-centric are you? Henley Business School, University of Reading, Reading, UK.

Cronbach, L.J. (1970). Essential of psychology testing. 3rd ed, Harper and Row Publishers Inc, New York, USA.

Day, J. (2013). Emerging Definitions of Boutique and Lifestyle hotels: A Delphi Study. Journal of Travel \& Tourism Marketing, 30, 715-731.

Fakfare, P., Talawanich, S., Pongwat, A., \& Chon, K. (2019). Asianness in hospitality: The case of luxury hotels in Bangkok, Thailand. ASEAN Journal of Management \& Innovation, 6(2), 77-92.

Gołąb-Andrzejak, E., \& Gębarowski, M. (2018). Creating hotel services from a perspective of extraordinary customer experience. Handel Wewnętrzny, 4(375), 89-100.

Kalanon, K. (2012). Hotel brand equity: A case study of Dusit Thani Bangkok. Thesis (Master's degree), The Graduate School, Silpakorn University, Bangkok, Thailand.

Kandampully, J., Zhang, T., \& Jaakkola, E. (2018). Customer experience management in hospitality: A literature synthesis, new understanding, and research agenda. International Journal of Contemporary Hospitality Management, 30(1), 21-56. https://doi.org/10.1108/IJCHM-10-2015-0549

Kasivivat, S. (2018). Tourism experience design. Seminar in tourism experience design, Institute of Development Administration, Bangkok, Thailand.

Khadka, K., \& Maharjan, S. (2017). Customer satisfaction and customer loyalty: Case Trivsel Städtjänster (Trivsel siivouspalvelut), Centria University of Applied Sciences, Finland.

Khan, I., Garg, R.J., \& Rahman, Z. (2015). Customer Service Experience in Hotel Operations: An Empirical Analysis. Procedia - Social and Behavioral Sciences, 189, 266-274. https://doi.org/10.1016/j.sbspro.2015.03.222.

Kongpolphrom, W. (2018). Thainess realisation in selected travel websites. Journal of Thai Interdisciplinary Research, 13(4), 63-67.

Kozak, M.A., \& Acar, D. (2015). Service design in hotels: A conceptual review. Tourism: An International Interdisciplinary Journal, 63(2), 225-240.

Lemon, K.N., \& Verhoef, P.C. (2016). Understanding customer experience throughout the customer journey. Journal of Marketing, 80(6), 69-96.

Nirattrakul, Y. (2015). Amazing Thailand. TAT Review, 1(1), 67-73.

Nunnally, J.C. (1978). Psychometric theory. 2nd Edition, McGraw-Hill, New York, USA.

Pine, B.J., \& Gilmore, J.H. (1998). Welcome to the Experience Economy. Harvard Business Review, (July- August), 97-105.

Sassen, S., \& Kourtit, K. (2021). A Post-Corona Perspective for Smart Cities: 'Should I Stay, or Should I Go?' Sustainability, $13,9988$. https://doi.org/10.3390/su13179988

Seligman, J. (2018). Customer experience management "The experiential journey. University of Southampton, Southampton, UK.

Sucher, W., Pusiran, A.K., Dhevabanchachai, N., \& Chon, K. (2013). The Influences of Asian Cultural Values in the Asian Hospitality Services. The1 1th APacCHRIE Conference (pp. 21-24). Macau SAR, China.

Sukkha, A., \& Peinroj, N. (2015). Customer Experience Management Guideline for Developing Performance of Hotel' Business in Phuket Province. Srinakarinwirot Business Administration Journal, 6(2), 74-83.

Supploy, S. (2018). Learning and Development Manager, Bangkok Marriott the Surawongse. (9 August). Interview.

Toubes, D.R., Araújo Vila, N., \& Fraiz Brea, J.A. (2021). Changes in Consumption Patterns and Tourist Promotion after the COVID-19 Pandemic. Journal of Theoretical and Applied Electronic Commerce Research, 16, 1332-1352. https://doi.org/10.3390/jtaer16050075

Vanichbuncha, K. (2019). Analysis of structural equations (SEM) with AMOS, Chulalongkorn University Book Centre, Bangkok, Thailand.

Zhong, Y.Y., Busser, J.A., \& Baloglu, S. (2017). A model of memorable tourism experience: The effects on satisfaction, affective commitment, and storytelling. Tourism Analysis, 22(2), 201-217.

****Department of Cultural Promotion, Ministry of Culture. (2016). Culture, way of life and wisdom, Rung Silp Printing, Bangkok, Thailand.

*** Tourism Authority of Thailand (TAT). (2015). Amazing Thailand. TAT Review, 1(1), 67-73.

Article history: Received: 12.08.2021 Revised: 06.12.2021 Accepted: 06.01.2022 Available online: 31.01 .2022 